\title{
Complete genome sequence of Leuconostoc gelidum subsp. gasicomitatum KG16-1, isolated from vacuum-packaged vegetable sausages
}

\author{
Margarita Andreevskaya ${ }^{1 *}$, Jenni Hultman², Per Johansson², Pia Laine ${ }^{1}$, Lars Paulin', Petri Auvinen ${ }^{1}$
} and Johanna Björkroth²

\begin{abstract}
Leuconostoc gelidum subsp. gasicomitatum is a predominant lactic acid bacterium (LAB) in spoilage microbial communities of different kinds of modified-atmosphere packaged (MAP) food products. So far, only one genome sequence of a poultry-originating type strain of this bacterium $\left(L M G 18811^{\top}\right)$ has been available. In the current study, we present the completely sequenced and functionally annotated genome of strain KG16-1 isolated from a vegetable-based product. In addition, six other vegetable-associated strains were sequenced to study possible "niche" specificity suggested by recent multilocus sequence typing. The genome of strain KG16-1 consisted of one circular chromosome and three plasmids, which together contained 2,035 CDSs. The chromosome carried at least three prophage regions and one of the plasmids encoded a galactan degradation cluster, which might provide a survival advantage in plant-related environments. The genome comparison with LMG $18811^{\top}$ and six other vegetable strains suggests no major differences between the meat- and vegetable-associated strains that would explain their "niche" specificity. Finally, the comparison with the genomes of other leuconostocs highlights the distribution of functionally interesting genes across the L. gelidum strains and the genus Leuconostoc.
\end{abstract}

Keywords: Leuconostoc gelidum subsp. gasicomitatum, Food spoilage, Functional genome annotation, Comparative genomic analysis, Modified-atmosphere packaging, Vegetable products

\section{Introduction}

Leuconostoc gelidum is a psychrotrophic LAB commonly associated with cold-stored nutrient-rich foods of meat and vegetable origins [1-7]. According to a recently published reclassification study, this species comprises three subspecies: L. gelidum subsp. gelidum, L. gelidum subsp. gasicomitatum and L. gelidum subsp. aenigmaticum [8].

L. gelidum subsp. gasicomitatum was first isolated from spoiled MAP tomato-marinated broiler meat [2]. Later, it was found in spoiled MAP beef and pork $[3,9]$, and acetic-acid preserved herring [10]. Recently, it was detected in connection with the spoilage of boiled eggs preserved in brine [11], vacuum-packaged vegetable

\footnotetext{
* Correspondence: margarita.andreevskaya@helsinki.fi

${ }^{1}$ Institute of Biotechnology, University of Helsinki, Viikinkaari 5D, 00790

Helsinki, Finland

Full list of author information is available at the end of the article
}

sausages [4] and minimally processed vegetable salads [5]. Depending on the product type, the spoilage is characterized by the formation of gas, slime, sour and buttery off-odors, and discoloration. Together with $L$. gelidum subsp. gelidum, it belongs to the predominant microbiota at the end of shelf-life in different kinds of packaged cold-stored food products [5, 12].

Based on the previous studies of the genetic diversity and population structure of L. gelidum subsp. gasicomitatum, some strains isolated from vegetable-based products were almost not recovered from meat-derived foods $[9,13]$. This might suggest "niche-specificity" of the different strains as a consequence of their genetic differences. Alternatively, the absence of strain dissemination between vegetable- and meat-processing chains was proposed as a possible factor accounting for the phenomenon observed [9]. 
So far, only the complete genome of L. gelidum subsp. gasicomitatum type strain LMG $18811^{\mathrm{T}}$ isolated from spoiled MAP broiler meat, has been available [14]. In this study we present the complete and annotated genome sequence for the vegetable spoilage-associated strain L. gelidum subsp. gasicomitatum KG16-1 [4]. In addition, six more vegetable strains of this organism were sequenced and partially assembled. This allowed us to compare the gene repertoires of eight L. gelidum subsp. gasicomitatum strains and all leuconostocs sequenced to date to identify: i) the genetic determinants putatively accounting for the differences in lifestyle of meat and vegetable strains of the described organism, and ii) genes that are specific for the L. gelidum (subsp. gasicomitatum) species.

\section{Organism information}

\section{Classification and features}

L. gelidum subsp. gasicomitatum KG16-1 is a Grampositive, non-motile, non-sporulating, facultatively anaerobic psychrotrophic LAB, belonging to the phylum Firmicutes as part of the Leuconostocaceae family (Table 1). It was first isolated from spoiled vacuumpackaged vegetable sausages in 2006 in Helsinki, Finland (the strain was initially designated as $16-1$ and then renamed into KG16-1) [4]. The sausages consisted mainly of carrot (56\%) with the addition of potato, rapeseed oil, cheese, cream, egg yolk powder and sucrose, and were stored below $8{ }^{\circ} \mathrm{C}$ for more than 20 days after cooking and packaging. The spoilage was characterized by the formation of gas and slime. Inoculation

Table 1 Classification and general features of Leuconostoc gelidum subsp. gasicomitatum strain KG16-1 according to MIGS recommendations [48]

\begin{tabular}{|c|c|c|c|}
\hline MIGS ID & Property & Term & Evidence code $^{a}$ \\
\hline & Classification & Domain Bacteria & TAS [49] \\
\hline & & Phylum Firmicutes & $\operatorname{TAS}[50,51]$ \\
\hline & & Class Bacilli & TAS [52] \\
\hline & & Order Lactobacillales & TAS [53] \\
\hline & & Family Leuconostocaceae & TAS [54] \\
\hline & & Genus Leuconostoc & TAS [55-57] \\
\hline & & Species Leuconostoc gelidum & $\operatorname{TAS}[1,8]$ \\
\hline & & Subspecies Leuconostoc gelidum subsp. gasicomitatum & $\operatorname{TAS}[2,8]$ \\
\hline & & Strain KG16-1 & \\
\hline & Gram stain & Positive & TAS [2] \\
\hline & Cell shape & Coccus & TAS [2] \\
\hline & Motility & Non-motile & TAS [2] \\
\hline & Sporulation & Not reported & NAS \\
\hline & Temperature range & Psychrotroph & TAS [2] \\
\hline & Optimum temperature & $25^{\circ} \mathrm{C}$ & TAS [2] \\
\hline & pH range; Optimum & $5-8 ; 6.5$ & TAS $[8,58]$ \\
\hline & Carbon source & $\begin{array}{l}\text { D-glucose, D-fructose, D-mannose, L-arabinose, D-ribose, } \\
\text { methyl D-glucoside, D-cellobiose, D-maltose, D-lactose, } \\
\text { D-melibiose, D-raffinose, D-saccharose, D-trehalose, D-turanose }\end{array}$ & IDA \\
\hline MIGS-6 & Habitat & Vacuum-packaged vegetable sausages & TAS [4] \\
\hline MIGS-6.3 & Salinity & $4 \% \mathrm{NaCl}(\mathrm{w} / \mathrm{v})$ & TAS [8] \\
\hline MIGS-22 & Oxygen requirement & Facultative anaerobic & TAS [59] \\
\hline MIGS-15 & Biotic relationship & Free-living & NAS \\
\hline MIGS-14 & Pathogenicity & Non-pathogen & NAS \\
\hline MIGS-4 & Geographic location & Helsinki, Finland & TAS [4] \\
\hline MIGS-5 & Sample collection & 2006 & TAS [4] \\
\hline MIGS-4.1 & Latitude & 60.19 & NAS \\
\hline MIGS-4.2 & Longitude & 24.94 & NAS \\
\hline MIGS-4.4 & Altitude & Unknown & NAS \\
\hline
\end{tabular}

${ }^{a}$ Evidence codes - IDA: Inferred from Direct Assay; TAS: Traceable Author Statement (i.e., a direct report exists in literature); NAS: Non-traceable Author Statement (i.e., not directly observed for the living, isolated sample, but based on a generally accepted property for the species, or anecdotal evidence). These evidence codes are from the Gene Ontology project [60] 
experiments showed [4] that strain KG16-1 alone is able to cause spoilage of vacuum-packaged vegetable sausages. The phylogenetic analysis based on the concatenated nucleotide sequences of atpA, pheS and rpoA genes (coding for ATP synthase subunit alpha, phenylalanine-tRNA ligase alpha subunit and DNA-directed RNA polymerase subunit alpha, respectively, and showed to successfully discriminate between species of the genus Leuconostoc [15]) clearly shows that strain KG16-1 belongs to the species L. gelidum subspecies gasicomitatum and is distinct from the subspecies gelidum and aenigmaticum (Fig. 1). According to the API $50 \mathrm{CH}$ carbohydrate utilization test (bioMérieux, Marcy l'Etoile, France), this bacterium is capable of fermenting a variety of carbohydrates, including hexoses, pentoses and disaccharides (Table 1). The utilization of D-galactose, $\mathrm{N}$-acetylglucosamine and gentibiose is weak. Peculiarly, unlike the majority of L. gelidum subsp. gasicomitatum strains, strain KG161 does not ferment xylose. The cells are oval cocci, 0.5 to $1 \mu \mathrm{m}$ in diameter (Fig. 2). Colonies formed on de Man-Rogosa-Sharpe (MRS) medium are small and greyish-white.

\section{Genome sequencing information}

\section{Genome project history}

Strain KG16-1 was chosen for sequencing as a representative of a vegetable-based product spoilage-associated strain of L. gelidum subsp. gasicomitatum. The manufacturer of the product was a small-size operator using vegetables as the main ingredients. No meat was handled at the plant and the other ingredients were mainly heat treated. Since this was the first wider problem reported affecting non-meat foods, and more than one product of the manufacturer was affected, a genome project was initiated. The project was carried out jointly by the Institute of Biotechnology and Department of Food Hygiene and Environmental Health, University of Helsinki, Finland. The complete genome was sequenced, fully assembled and annotated. The summary of the project information, including database identifiers, is shown in Table 2.

\section{Growth conditions and genomic DNA preparation}

For DNA isolation, L. gelidum subsp. gasicomitatum strain KG16-1 was grown anaerobically (Oxoid, Basingstoke, United Kingdom) in MRS broth at $25^{\circ} \mathrm{C}$ overnight. DNA was extracted using a modified method [16] of Pitcher et al. [17], and the genomic DNA was mechanically sheared with a needle. The ratio of absorbance at $260 \mathrm{~nm}$ and $280 \mathrm{~nm}$ (NanoDrop spectrophotometer, Thermo Scientific, USA) as a measure of DNA purity was assessed to be $\sim 1.8$.

\section{Genome sequencing and assembly}

Genomic DNA was sequenced using 454 Sequencer with GS Flx chemistry. The 152,753 reads obtained had an average length of $224 \mathrm{bp}$ and were assembled using Newbler 2.0.00.20. In total, 149,580 reads (97.9 \%) were assembled, resulting in 106 large ( $>500$ bp) and 12 smaller ( $>100 \mathrm{bp}$, but $<500 \mathrm{bp}$ ) contigs with N50 contig size being $32,090 \mathrm{bp}$. The average sequencing coverage was $19 \times$. The Gap4 program from the Staden package

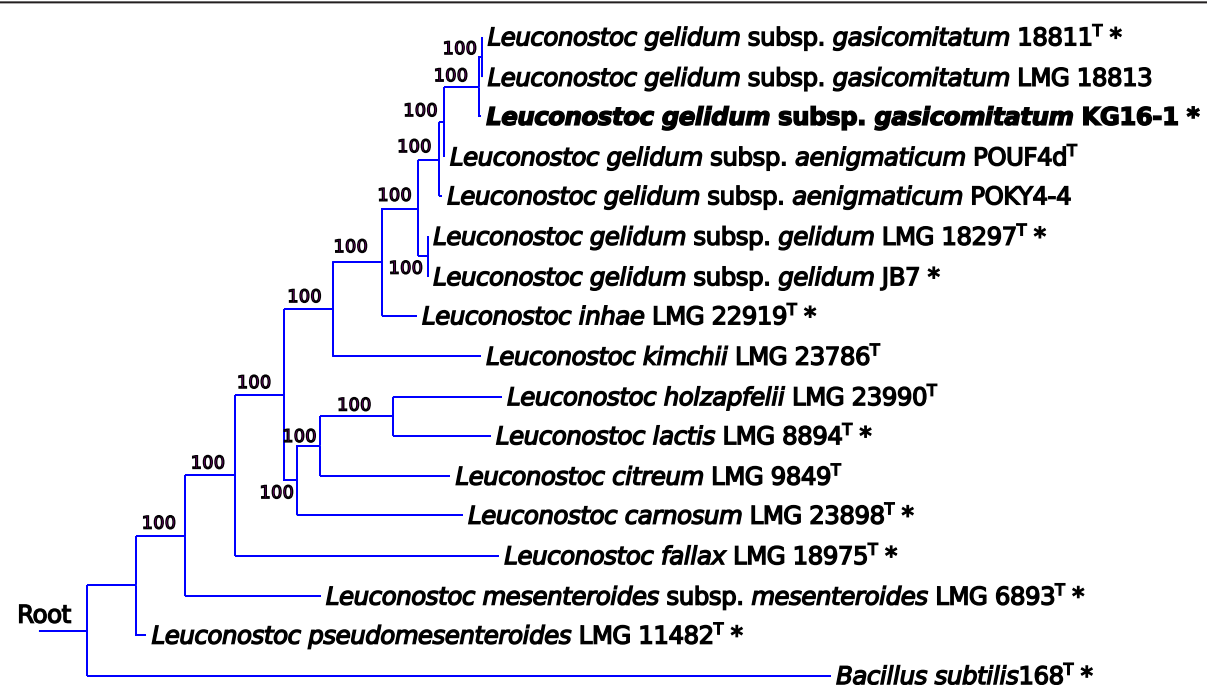

Fig. 1 Phylogenetic tree showing the relationship of L. gelidum subsp. gasicomitatum KG16-1 to other Leuconostoc species. The tree was built using T-REX web server [61] based on MUSCLE [62] aligned concatenated nucleotide sequences of atpA, pheS and rpoA genes (Genbank identifiers are listed in Table S1 of Additional file 1). Poorly aligned positions were removed using Gblocks [63] with default parameters and the tree was inferred using RAxML program [64] with GTRCAT substitution model and Bacillus subtilis as an outgroup. Bootstrap analysis was performed with 500 replicates. Type strains are identified with superscripted "T" and the availability of a sequenced genome is indicated with "**" 


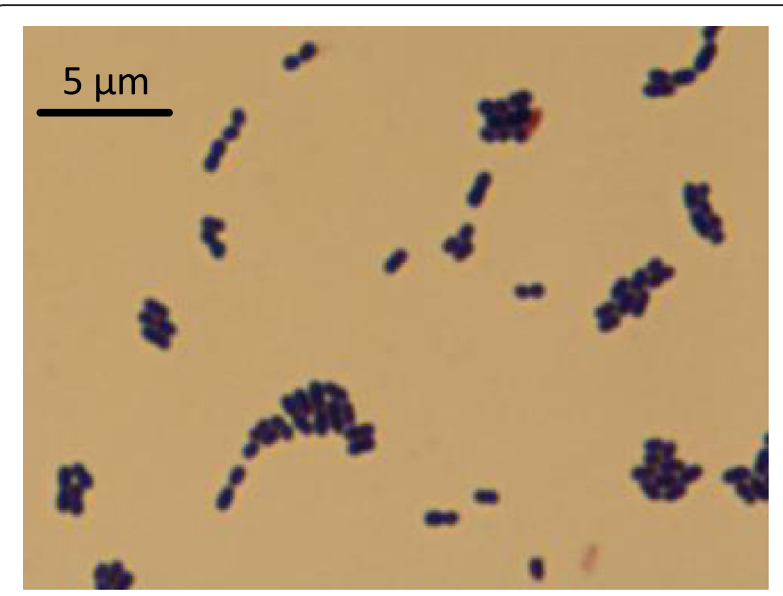

Fig. 2 Photomicrograph of L. gelidum subsp. gasicomitatum KG16-1. The cells were grown for $48 \mathrm{~h}$ on the plate with MRS medium and Gram stained. The image was taken using an optical microscope with magnification 1000x

[18] was first used to design primers to the near ends ( 150-200 bp) of the contigs and then to organize the contigs in the correct order based on the PCR products. Gaps were closed by Sanger sequencing with BigDye v3.1 chemistry and primer walking of PCR products. List of primers used can be obtained upon request. The insertion of A nucleotide (genomic position 416,796) within the mucus-binding proteinencoding gene LEKG_0412 was confirmed by linker adaptor-mediated PCR. For this, genomic DNA was digested by EcoRI restriction enzyme and then ligated to synthetic adaptors that provided binding sites for primers used during PCR amplification (5' GCATT

Table 2 Project information

\begin{tabular}{lll}
\hline MIGS ID & Property & Term \\
\hline MIGS 31 & Finishing quality & Complete \\
MIGS-28 & Libraries used & 454 fragment library (500-600 bp) \\
MIGS 29 & Sequencing platforms & 454 Sequencer with GS Flx chemistry \\
MIGS 31.2 & Fold coverage & $19 \times$ \\
MIGS 30 & Assemblers & $\begin{array}{l}\text { Newbler 2.0.00.20, Gap4 from } \\
\text { Staden package }\end{array}$ \\
MIGS 32 & Gene calling method & Prodigal, Glimmer3, tRNAscan-SE, \\
& & RNAmmer, ARAGORN \\
& Locus Tag & LEKG \\
& Genbank ID & LN890331- LN890334 \\
& GenBank Date of & January 20, 2016 \\
& Release & BIOPROJECT \\
MIGS 13 & Source Material & KG16-1 \\
& Identifier & \\
& Project relevance & Food spoilage \\
\hline
\end{tabular}

CACACTTAAGTTTCGTGA '3 and 5' TGTCGAC GTTGTAAAACGACGGCCAGT $3{ }^{\prime}$ ) and Sanger sequencing (5' ATTAACCCTCACTAAAGGGA 3').

\section{Genome annotation}

Protein-coding genes were identified by Glimmer3 [19] and Prodigal [20] and their functions were predicted by RAST [21] and PANNZER [22]. The outputs of two programs for the prediction of gene coordinates as well as for gene function prediction were compared and the discrepancies were manually resolved based on the presence of potential ribosomal binding sites, similarity searches against public databases and literature data. To further improve the gene prediction, the GenePRIMP pipeline [23], which detects erroneously predicted translational start sites, broken and missing genes, was applied. To identify putative pseudogenes and possible sequencing errors, frameshift prediction was performed using GeneTack program [24] and similarity searches with proteomes of closely related species using Exonerate [25]. Bacteriocins and prophage regions were predicted with the help of BAGEL2 [26] and PHAST [27] programs, respectively. CRISPRFinder [28] was used to detect CRISPRs. rRNA, tRNA and tmRNA, were predicted with RNAmmer [29], tRNAscan-SE [30] and ARAGORN [31], respectively. Identification of transmembrane helices and signal peptides was performed with TMHMM server v. 2.0 [32] and SignalP 4.1 server [33]. Finally, the assignment of COG functional categories and prediction of Pfam domains were performed by an RPS-BLAST search (e-value threshold of 0.01 was used and the one best hit was taken into account for each gene) against the COG and Pfam databases, respectively. The genome was also checked for the presence of all core COG functions [34].

\section{Genome properties}

The complete genome of L. gelidum subsp. gasicomitatum KG16-1 consisted of one circular chromosome $(1,965,841 \mathrm{bp})$ and three circular plasmids $(35,714 \mathrm{bp}$, $29,494 \mathrm{bp}$ and $19,683 \mathrm{bp}$ ) (Table 3). The average GC content of the chromosome was $36.9 \%$. The numbers of predicted protein-coding genes were 1,944 (including 12 pseudogenes) on the chromosome and 38 (including two pseudogenes), 32 and 21 on the three plasmids,

Table 3 Summary of genome: one chromosome and three plasmids

\begin{tabular}{lcll}
\hline Label & Size $(\mathrm{Mb})$ & Topology & INSDC identifier \\
\hline Chromosome & 1.97 & Circular & LN890331 \\
Plasmid 1 & 0.04 & Circular & LN890332 \\
Plasmid 2 & 0.03 & Circular & LN890333 \\
Plasmid 3 & 0.02 & Circular & LN890334 \\
\hline
\end{tabular}


respectively (Table 4). In addition, the chromosome contained four rRNA operons (each having 5S, 16S and 23S rRNAs), 67 tRNA genes and one tmRNA gene. The putative function was assigned to $84 \%$ of genes and COGs were assigned to 1,601 protein-coding genes $(78.7 \%$ of the total). The distribution of the protein-coding genes among COG functional categories is summarized in Table 5 and depicted in Fig. 3. All 61 core COGs of the minimal set of essential functions for a prokaryotic organism [34] were present in the genome. The genome harbored three complete prophages (LEKG_0833-0885; LEKG_1279-1342; LEKG_1560-1576) (Fig. 3). However, due to the presence of bacteriophage attachment sites inside the second prophage region, it might consist of two different prophages.

\section{Insights from the genome sequence Genome functional characteristics}

Based on the predicted functions in the genome, $L$. gelidum subsp. gasicomitatum strain KG16-1 had a very similar set of metabolic pathways to those present in strain LMG $18811^{\mathrm{T}}$ and described previously [14]. Briefly, the only central carbohydrate catabolic pathway present in the genome was the phosphoketolase pathway, which classifies this bacterium as obligate heterofermentative LAB. The genome also contained genes for three alternative pyruvate utilization pathways, respiratory electron transport chain and menaquinone biosynthesis. Despite the negative reaction for xylose utilization, the required xylose catabolic genes $(x y l A$ and $x y l B)$ and putative xylose transporter (xylP, LEKG_1853) were present in the genome and did not contain frameshifts or premature stop codons. However, an amino acid sequence comparison

Table 4 Genome statistics

\begin{tabular}{lll}
\hline Attribute & Value & \% of Total \\
\hline Genome size (bp) & $2,050,732$ & 100.0 \\
DNA coding (bp) & $1,829,560$ & 89.2 \\
DNA G + C (bp) & 755,745 & 36.9 \\
DNA scaffolds & 4 & \\
Total genes & 2,115 & 100.0 \\
Protein coding genes & 2,035 & 96.2 \\
RNA genes & 80 & 3.8 \\
Pseudo genes & 14 & 0.7 \\
Genes in internal clusters & NA & NA \\
Genes with function prediction & 1,777 & 84.0 \\
Genes assigned to COGs & 1601 & 75.7 \\
Genes with Pfam domains & 1688 & 79.8 \\
Genes with signal peptides & 66 & 3.1 \\
Genes with transmembrane helices & 543 & 25.7 \\
CRISPR repeats & 0 & 0 \\
\hline
\end{tabular}

Table 5 Number of genes associated with general COG functional categories

\begin{tabular}{|c|c|c|c|}
\hline Code & Value & $\%$ age & Description \\
\hline J & 190 & 9.3 & Translation, ribosomal structure and biogenesis \\
\hline A & 0 & 0.0 & RNA processing and modification \\
\hline K & 144 & 7.1 & Transcription \\
\hline L & 102 & 5.0 & Replication, recombination and repair \\
\hline B & 0 & 0.0 & Chromatin structure and dynamics \\
\hline $\mathrm{D}$ & 31 & 1.5 & $\begin{array}{l}\text { Cell cycle control, cell division, chromosome } \\
\text { partitioning }\end{array}$ \\
\hline V & 52 & 2.6 & Defense mechanisms \\
\hline T & 56 & 2.8 & Signal transduction mechanisms \\
\hline M & 105 & 5.2 & Cell wall/membrane biogenesis \\
\hline N & 14 & 0.7 & Cell motility \\
\hline U & 21 & 1.0 & Intracellular trafficking and secretion \\
\hline $\mathrm{O}$ & 57 & 2.8 & $\begin{array}{l}\text { Posttranslational modification, protein turnover, } \\
\text { chaperones }\end{array}$ \\
\hline C & 60 & 2.9 & Energy production and conversion \\
\hline G & 177 & 8.7 & Carbohydrate transport and metabolism \\
\hline$E$ & 132 & 6.5 & Amino acid transport and metabolism \\
\hline $\mathrm{F}$ & 90 & 4.4 & Nucleotide transport and metabolism \\
\hline H & 79 & 3.9 & Coenzyme transport and metabolism \\
\hline I & 66 & 3.2 & Lipid transport and metabolism \\
\hline$P$ & 79 & 3.9 & Inorganic ion transport and metabolism \\
\hline Q & 25 & 1.2 & $\begin{array}{l}\text { Secondary metabolites biosynthesis, transport } \\
\text { and catabolism }\end{array}$ \\
\hline $\mathrm{R}$ & 133 & 6.5 & General function prediction only \\
\hline S & 108 & 5.3 & Function unknown \\
\hline - & 434 & 21.3 & Not in COGs \\
\hline
\end{tabular}

The total is based on the total number of protein coding genes in the genome

of $x y l A$ and $x y l B$ between xylose-fermenting (according to API 50CH test) L. gelidum subsp. gasicomitatum strains (LMG 18811 ${ }^{\mathrm{T}}$, C120c, KSL4-2 and PL111) and KG16-1 showed that in KG16-1, these genes carried two (V168A, S260G) and four (S108L, L128H, D199N, G319E) amino acid substitutions, respectively, which were not present in other xylose-utilizing strains. In addition, KG16-1 was lacking the ortholog of another xylose transporter $x y l T$ (e.g. gene LEGAS_1062 in LMG $18811^{\mathrm{T}}$ ), which was present in other strains. D-Ala-D-Ala ligase gene $d d l$ (LEKG_0342) contained $\mathrm{Phe}^{261}$ in its active site, which indicates a resistance to vancomycin [35]. The same was found for all other leuconostocs sequenced to date, when sequences of $d d l$ genes were aligned. Unlike the genome of strain LMG $18811^{\mathrm{T}}$, strain KG16-1 contained three plasmids. The first plasmid contained the putative type I galactan catabolic gene cluster (LEKG_1953-1960), similar to the cluster present in Leuconostoc mesenteroides subsp. mesenteroides ATCC 8293 [36], and heavy metal resistance genes. Type I 


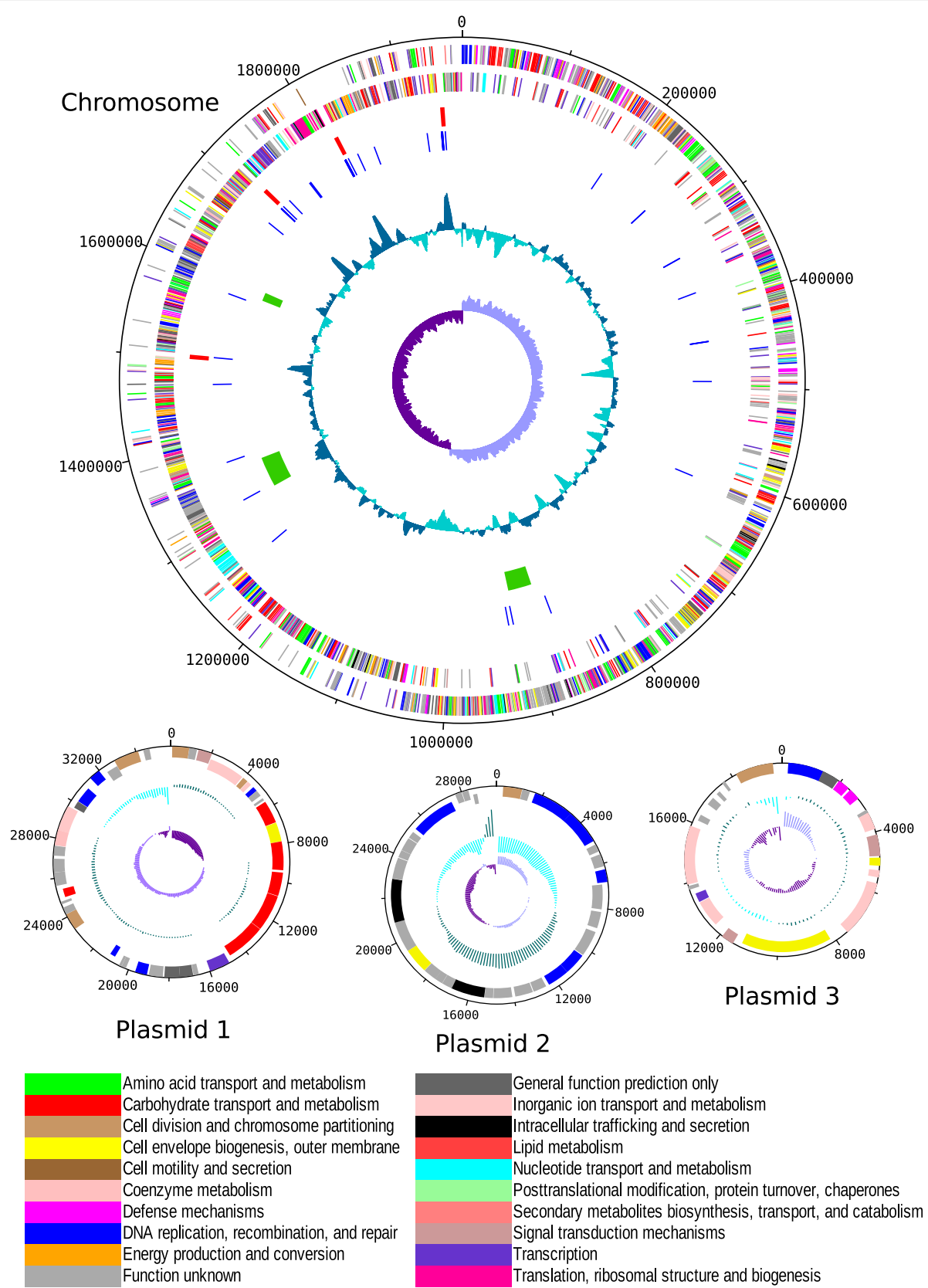

Fig. 3 Genome map of L. gelidum subsp. gasicomitatum KG16-1. Genes are colored according to their COG functional annotations. Moving inwards, the tracks on the chromosome map represent the following features: genes on the forward strand, genes on the reverse strand, rRNAgenes (red), tRNAgenes (blue) prophages (green), GC plot (cyan), and GC skew (purple). Likewise, the tracks on the plasmid maps represent the genes on the forward and reverse strands, GC plot, and GC skew

galactan is a structural polysaccharide comprising pectin, which is one of the major components of plant cell walls. Hence, the ability to degrade this polysaccharide would be beneficial for the growth in a plant environment. The second plasmid harbored a Type II restriction-modification (RM) system and conjugal transfer genes, while the third plasmid carried an RM system (the type is unclear) and heavy-metal resistant genes. In addition to the plasmids, the chromosome harbored at least two RM enzymes of type II (LEKG_0442 and LEKG_0445).

\section{Genomic comparison between L. gelidum subsp.} gasicomitatum strains and other Leuconostoc species

The comparison of gene contents (more precisely, their protein translations) was performed for $L$. gelidum subsp. gasicomitatum KG16-1 and 40 other leuconostocs 
(assembly accession numbers are listed in Table S2 of Additional file 1). They comprised 34 sequenced and annotated genomes available at the NCBI database by September 2015, including the complete genome of $L$. gelidum subsp. gasicomitatum LMG $18811^{\mathrm{T}}$. In addition, we sequenced six strains of L. gelidum subsp. gasicomitatum (C120c, C122c, KSL4-2, PB1a, PB1e, PL111) associated with spoilage of other vegetable-based food products (Table 6). The sequencing was done using Illumina HiSeq2500 platform (paired-end library with the read length of $101+$ $101 \mathrm{bp})$, the draft genomes were assembled with Velvet 1.2.08 [37] and annotated by RAST [21]. The important details on the draft genomes, such as genome size, fold coverage, number of contigs and predicted CDSs, are given in Table S3 of Additional file 1.

Overall, the genome set for comparative analysis contained eight L. gelidum subsp. gasicomitatum genomes (two complete and six draft). Ortholog prediction and subsequent analysis, including pangenome matrix (Additional file 2) construction and identification of group-specific genes, were performed using GET_HOMOLOGUES software package [38] with OrthoMCL clustering algorithm [39] and default parameters (minimum coverage in BLAST pairwise alignments $75 \%$, maximum e-value 0.00001), except for the minimum sequence identity, which was set to $30 \%$.

As a result 6,248 orthologous groups were predicted (including singletons) with 406 clusters present in all genomes (so-called core genome), and 983 present in at least $95 \%$ (38) of the genomes (Additional file 2). The last number represents the soft core of the Leuconostoc genus, which allowed to account for the missing annotations in draft genomes [40]. The soft core included 52 clusters with unknown function. Based on the pangenome matrix of the presence/absence of the genes in the genomes, a pangenome tree was constructed (Fig. 4). Generally, genomes belonging to the same species clustered together, except for the genomes of L. gelidum subsp. gasicomitatum 1301_LGAS and L. citreum 1300_LCIT obtained during the same study of clinical isolates from the hospital intensive care unit [41], where species names were assigned to the sequenced genomes based on the best matching genome from NCBI database. The first genome clustered together with $L$. citreum strains, while the second genome fell into the same branch with $L$. lactis strains. The phylogenetic analysis (Figure S1 of Additional file 1) placed these genomes into the same branches as in the pangenome tree, thereby confirming that the first genome, formerly assigned to L. gelidum subsp. gasicomitatum (1301_LGAS), actually belongs to L. citreum, while the second genome, assigned to L. citreum (1300_LCIT), is a member of the L. lactis group. In addition, the phylogenetic analysis (Figure S1 of Additional file 1) showed that the genome assigned to L. inhae LMG 22919 (= KCTC 3774) appears to be of L. gelidum subsp. gasicomitatum strain. It is notable that none of the previously published gene sequences for $L$. inhae LMG 22919 (= KCTC 3774) (16S rRNA [AF439560]; recN [GenBank:AM698028]; recA [GenBank:JF261010]; atpA [GenBank:AM711190]; pheS [GenBank:AM711167]; rpoA [GenBank:AM711310]) mapped $100 \%$ to the genome assigned to the same $L$. inhae strain [GenBank:GCF_000166735.2]. Instead, the nucleotide sequences of these genes extracted from this genome were identical to those of $L$. gelidum subsp. gasicomitatum 18811 ${ }^{\mathrm{T}}$ [GenBank: GCA_000196855.1]. However, the genome assigned to L. inhae LMG 22919 lacked five genomic regions (including two prophages) that are present in L. gelidum subsp. gasicomitatum $18811^{\mathrm{T}}$ genome, but absent in all or some other $L$. gelidum subsp. gasicomitatum strains (Fig. 5a). This might indicate that the considered genome [GenBank:GCF_000166735.2] belongs to the L. gelidum subsp. gasicomitatum strain, which is very close to strain $18811^{\mathrm{T}}$, but not identical. The clustering of the genome assigned to L. inhae LMG 22919 together with L. fallax on the pangenome tree (Fig. 4) was, assumingly, the result of numerous frameshifts that are present in this genome (most probably due to the sequencing errors), as well as the high genome fragmentation (893 contigs), which both caused many genes to be missing or truncated in the genome annotation. Although phylogenetically $L$. carnosum was closer to L. citreum and L. lactis (Fig. 1 ), in terms of gene content it seemed to be more similar to L. kimchii (Fig. 4). Interestingly, there was no clear separation between the meat strain and vegetable strains of $L$. gelidum subsp. gasicomitatum based on gene content. On the contrary, five vegetable strains clustered together with the meat strain, while the three remaining vegetable strains formed a separate branch.

L. gelidum subsp. gasicomitatum KG16-1 genome contained 75 unique genes that are not present in other Leuconostoc genomes. Of these genes, uncharacterized and phage protein-coding genes constituted $77 \%$ (58) (Fig. 5b). The genome contained the cluster for lacticin481 biosynthesis (LEKG_0458-0465), which was also present only in L. gelidum subsp. gasicomitatum strain $\mathrm{C} 120 \mathrm{c}$ and homologies to that in Lactococcus lactis subsp. lactis [42, 43]. The lacticin-481 type bacteriocin has been shown to be active against LAB and foodspoilage bacterium Clostridium tyrobutyricum [43]. Genes involved in catabolism of type I galactan were present in other vegetable strains of $L$. gelidum subsp. gasicomitatum besides KG16-1 (KSL4-2, PL111 and PB1e). Peculiarly, the 
Table 6 The presence/absence of selected genes in L. gelidum strains

\begin{tabular}{|c|c|c|c|c|c|c|c|c|c|c|c|c|}
\hline Gene name & LMG $18811^{\top}$ & KG16-1 & C120c & $\mathrm{C} 122 \mathrm{C}$ & KSL4-2 & PB1a & PB1e & PL111 & LMG $22919^{a}$ & LMG $18297^{\top}$ & JB7 & Other Leuconostocs \\
\hline Lacticin biosynthesis genes & - & + & $+^{\mathrm{b}}$ & - & - & - & - & - & - & - & - & - \\
\hline $\begin{array}{l}\text { Polyketide biosynthesis } \\
\text { cluster }\end{array}$ & + & - & + & + & + & + & - & + & $t^{\mathrm{b}, \mathrm{c}}$ & - & - & - \\
\hline Pyruvate oxidase & + & - & + & + & + & + & + & + & + & + & + & $\begin{array}{l}\text { Present in } 15 \text { other } \\
\text { leuconostocs }\end{array}$ \\
\hline Biofilm formation genes & + & - & + & + & + & + & + & + & $+t^{\mathrm{b}, \mathrm{c}}$ & + & + & $\begin{array}{l}\text { L. mesenteroides KFRI-MG, } \\
\text { L. mesenteroides subsp. } \\
\text { mesenteroides J18, } \\
\text { L. pseudomesenteroides } \\
\text { LMG } 11482^{\top}\end{array}$ \\
\hline Collagen-binding protein & + & - & + & + & + & + & + & + & $t^{\mathrm{b}, \mathrm{c}}$ & + & + & $\begin{array}{l}\text { Present in all four } L \text {. } \\
\text { pseudomesenteroides strains }\end{array}$ \\
\hline Xylose-proton symporter & + & - & + & + & + & + & + & + & $+t^{b, c}$ & + & + & $\begin{array}{l}\text { Present in } 15 \text { other } \\
\text { leuconostocs }\end{array}$ \\
\hline Mucus-binding protein & + & $t^{\mathrm{b}}$ & + & + & + & + & + & + & $t^{\mathrm{b}, \mathrm{c}}$ & - & - & - \\
\hline Accessory Sec system & + & + & + & + & + & + & + & + & $+^{\mathrm{b}, \mathrm{c}}$ & - & + & $\begin{array}{l}\text { L. fallax LMG } 18975^{\mathrm{a}, \mathrm{b}} \\
\text { L. pseudomesenteroides } \\
\text { LMG } 11482^{\mathrm{T}} \text {, } \\
\text { L. kimchii C2 (partially) }\end{array}$ \\
\hline $\begin{array}{l}\text { Fused glutamate racemase/ } \\
\text { NTP pyrophosphatase }\end{array}$ & + & + & + & + & + & + & + & + & $+t^{\mathrm{b}, \mathrm{c}}$ & + & + & $\begin{array}{l}\text { Encoded by two separate } \\
\text { genes }\end{array}$ \\
\hline Source of isolation & $\begin{array}{l}\text { Broiler } \\
\text { meat [2] }\end{array}$ & $\begin{array}{l}\text { Vegetable } \\
\text { sausages [4] }\end{array}$ & $\begin{array}{l}\text { Vegetable } \\
\text { salad [9] }\end{array}$ & $\begin{array}{l}\text { Vegetable } \\
\text { salad [13] }\end{array}$ & $\begin{array}{l}\text { Fish/carrots } \\
{[10]}\end{array}$ & Carrot [10] & Carrot [13] & Carrot [10] & Kimchi [65] & Kimchi [7] & Kimchi [6] & \\
\hline
\end{tabular}

Strains LMG 18811 ${ }^{\top}$, KG16-1, C120c, C122c, KSL4-2, PB1a, PB1e, PL111 and LMG 22919 belong to L. gelidum subsp. gasicomitatum; LMG $18297^{\top}$ and JB7 - to L. gelidum subsp. gelidum. Strains with complete genomes are LMG 18811 ${ }^{\top}$, KG16-1 and JB7; others have draft genomes. Gene names and locus_tags (either from KG16-1 or LMG 18811 ${ }^{\top}$ ): lacticin biosynthesis genes ICtA (LEKG_0458) and IctMT (LEKG_0461-0462); polyketide biosynthesis cluster (LEGAS_1827-1830); pyruvate oxidase poxB (LEGAS_1053); biofilm formation genes icaB and icaA (LEGAS_1065, LEGAS_1067); collagen-binding protein cna (LEGAS_1063); xylose-proton symporter xyIT (LEGAS_1062); mucus-binding protein (LEGAS_0414); accessory Sec system genes secY2, asp1, asp2, asp3, secA2, nss, gtfA, gtfB, asp4 (LEKG_0540-0548); fused glutamate racemase/NTP pyrophosphatase (LEKG_0672)

aPhylogenetic analysis (Figure S1 of Additional file 1) indicates that the genome, assigned to L. inhae LMG 22919, actually belongs to L. gelidum subsp. gasicomitatum species

${ }^{\mathrm{b}} \mathrm{Gene}$ is missing from the genome annotation

cContains frameshift(s) 


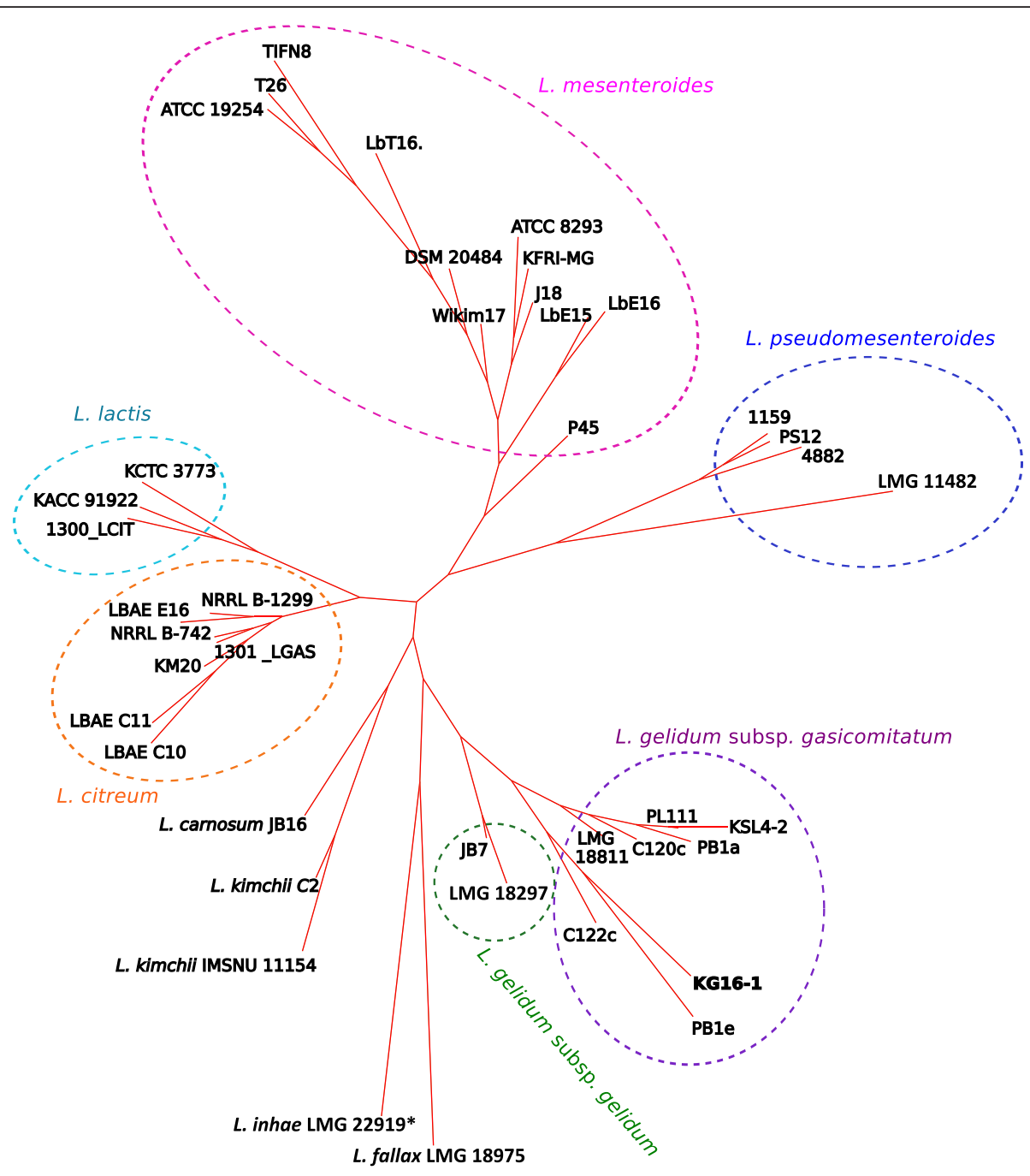

Fig. 4 Pangenome tree of the Leuconostoc genus, constructed based on information on presence/absence of orthologs. The tree was inferred using PARS program from the PHYLIP package [66] and visualized by the Tree viewer from T-REX web server [61]. *Phylogenetic analysis indicates that the genome assigned to $L$. inhae actually belongs to $L$. gelidum subsp. gasicomitatum. The clustering of this genome together with the $L$. fallax LMG 18975T genome was most likely caused by the numerous sequencing errors in this genome, as well as high genome fragmentation

KG16-1 genome was lacking several functionally interesting genes that are present in other L. gelidum strains (Table 6, Fig. 5a). They included a polyketide biosynthesis cluster and the genome locus containing pyruvate oxidase poxB, collagen-binding protein cna, biofilm formation genes icaAB and, as already mentioned, xylose transporter $x y l T$. Besides seven L. gelidum subsp. gasicomitatum strains, the same polyketide biosynthesis cluster (in terms of domain architecture and gene synteny) was found only in Streptococcus thermophilus JIM 8232 (genes pig-1,2,3,4). Polyketides are bioactive compounds that can exhibit antibacterial, immunosuppressive and antitumor activities [44]. Pyruvate oxidase is a hydrogen peroxide-producing enzyme and was speculated to be associated with meat discoloration [14]. Genes can and icaAB were suggested to mediate adhesion and, hence, better survival in meat environment of L. gelidum subsp. gasicomitatum LMG $18811^{\mathrm{T}}$ [14]. They exhibit homology to collagen adhesin and polysaccharide adhesin biosynthesis genes, respectively, from Staphylococcus aureus [45, 46]. Our analysis shows that, except for KG16-1, they were also present in vegetable strains. The orthologs of another putative adhesin, mucus-binding protein (LPxTG-like motif-containing), were found only in $L$. gelidum subsp. gasicomitatum strains. In the KG16-1 strain, this gene contained a frameshift due to the insertion of A nucleotide at the position 416,796 (confirmed by PCR and Sanger sequencing). Finally, an accessory Sec system involved in the export and 


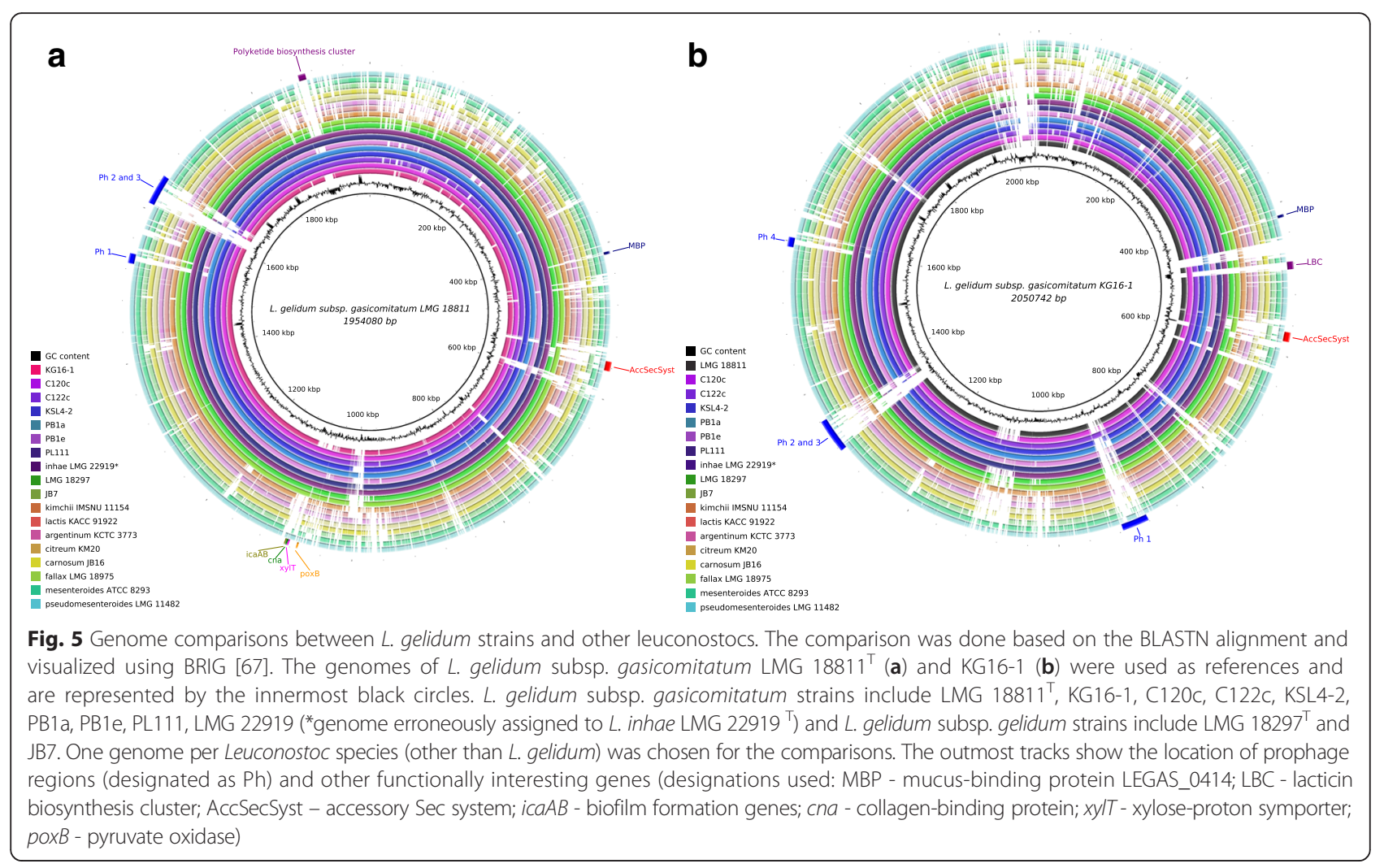

glycosylation of serine-rich adhesins [47] was only detected in a few Leuconostoc species, including L. gelidum strains (except for LMG $18297^{\mathrm{T}}$ ). Serine-rich proteins were found in the vicinity of this system in two complete genomes of L. gelidum subsp. gasicomitatum LMG $18811^{\mathrm{T}}$ and KG16-1. They were also present in other draft L. gelidum subsp. gasicomitatum genomes and might be involved in adhesion. The latter might play an important role in the survival and persistence of the bacteria considered in a food-processing environment.

\section{Conclusions}

Seven vegetable spoilage-associated strains of L. gelidum subsp. gasicomitatum were sequenced, and one (KG16-1) was fully assembled, functionally annotated and described in detail in this paper. The gene contents were compared between these vegetable strains, the meat-spoilageassociated strain LMG $18811^{\mathrm{T}}$ of the same species and 33 other Leuconostoc species sequenced to date. As a result, no obvious differences in gene contents between the meat strain and vegetable strains of $L$. gelidum subsp. gasicomitatum were found that would explain their adaptation to different ecological niches. Therefore, the absence of cross-contamination between vegetable- and meat-processing chains seems to be the more likely factor explaining strain segregation between vegetable- and meat-based food products. Finally, the distribution of functionally interesting genes (spoilage-, adhesionand bacteriocin-related) was determined across the $L$. gelidum strains and other leuconostocs.

\section{Additional files}

Additional file 1: Table S1. Genebank identifiers of the nucleotide sequences of atpA, pheS and rpoA genes, used for the phylogenetic analyses. Table S2. NCBI Refseq/Genbank assembly accession numbers for the comparative genomic analysis of Leuconostoc species (29.09.2015). Table S3. L. gelidum subsp. gasicomitatum draft genomes statistics. Figure S1. Phylogenetic tree showing the relationship of L. citreum 1300_LCIT, L. gelidum subsp. gasicomitatum 1301_LGAS and L. inhae LMG 22919 genomes to other Leuconostoc species. (PDF 406 kb)

Additional file 2: Pangenome matrix for Leuconostoc genus, core and softcore genes. (XLSX $1692 \mathrm{~kb}$ )

\section{Abbreviations \\ LAB, Lactic acid bacteria; MAP, Modified-atmosphere packaged; MRS, de Man-Rogosa-Sharpe (medium); RM, restriction-modification}

\section{Acknowledgements}

This project was funded by the Academy of Finland (grant no. 267755 and the Center of Excellence Program 2008-2013 in Microbial Food Safety Research). We also thank Integrative Life Science Doctoral Program (ILS) for supporting this study.

We appreciate the excellent technical assistance of Eeva-Marja Turkki, Kirsi Lipponen, Päivi Laamanen, Tuuli Pietilä, Lea Merviä, Ritva Rajala, Henna Niinivirta, and Erja Merivirta. Then last, but not least, we thank Stephen Skate for the language editing of the manuscript. 


\section{Authors' contributions}

MA performed the annotation of the complete L. gelidum subsp. gasicomitatum KG16-1 genome, comparative genomic analysis, interpretation of the results and wrote the manuscript. JH performed assembly and annotation of six draft L. gelidum subsp. gasicomitatum genomes, and helped to prepare the manuscript. PJ carried out phenotypic tests, participated in the annotation of the complete genome, interpretation of the results and preparing the manuscript. PL and LP performed the assembly of the complete genome and helped to prepare the manuscript. PA and JB participated in interpretation of the results and writing the manuscript. All authors read and approved the final manuscript.

\section{Competing interests}

The authors declare that they have no competing interests.

\section{Author details}

'Institute of Biotechnology, University of Helsinki, Viikinkaari 5D, 00790 Helsinki, Finland. ${ }^{2}$ Department of Food Hygiene and Environmental Health, University of Helsinki, Agnes Sjöbergin katu 2, 00790 Helsinki, Finland.

Received: 19 January 2016 Accepted: 31 May 2016

Published online: 07 June 2016

\section{References}

1. Shaw BG, Harding CD. Leuconostoc gelidum sp. nov. and Leuconostoc carnosum sp. nov. from chill-stored meats. Int J Syst Bacteriol. 1989:39:21723

2. Björkroth KJ, Geisen R, Schillinger U, et al. Characterization of Leuconostoc gasicomitatum sp. nov., associated with spoiled raw tomato-marinated broiler meat strips packaged under modified-atmosphere conditions. Appl Environ Microbiol. 2000;66:3764-72.

3. Vihavainen EJ, Björkroth KJ. Spoilage of value-added, high-oxygen modifiedatmosphere packaged raw beef steaks by Leuconostoc gasicomitatum and Leuconostoc gelidum. Int J Food Microbiol. 2007;119:340-5.

4. Vihavainen EJ, Murros AE, Björkroth KJ. Leuconostoc spoilage of vacuumpackaged vegetable sausages. J Food Prot. 2008;71:2312-5.

5. Pothakos V, Snauwaert C, De Vos P, Huys G, Devlieghere F. Psychrotrophic members of Leuconostoc gasicomitatum, Leuconostoc gelidum and Lactococcus piscium dominate at the end of shelf-life in packaged and chilled-stored food products in Belgium. Food Microbiol. 2014;39:61-7.

6. Jung JY, Lee SH, Jeon CO. Complete genome sequence of Leuconostoc gelidum strain JB7, isolated from kimchi. J Bacteriol. 2012;194:6665.

7. Kim D-S, Choi S-H, Kim D-W, et al. Genome sequence of Leuconostoc gelidum KCTC 3527, isolated from kimchi. J Bacteriol. 2011;193:799-800.

8. Rahkila R, De Bruyne K, Johansson P, Vandamme P, Björkroth J. Reclassification of Leuconostoc gasicomitatum as Leuconostoc gelidum subsp. gasicomitatum comb. nov., description of Leuconostoc gelidum subsp. aenigmaticum subsp. nov., designation of Leuconostoc gelidum subsp. gelidum subsp. nov. and emended description of Leuconostoc gelidum. Int J Syst Evol Microbiol. 2014;64:1290-5.

9. Vihavainen EJ, Björkroth KJ. Diversity of Leuconostoc gasicomitatum associated with meat spoilage. Int J Food Microbiol. 2009;136:32-6.

10. Lyhs U, Koort JMK, Lundström HS, Björkroth KJ. Leuconostoc gelidum and Leuconostoc gasicomitatum strains dominated the lactic acid bacterium population associated with strong slime formation in an acetic-acid herring preserve. Int J Food Microbiol. 2004;90:207-18.

11. Pothakos V, Taminiau B, Huys G, Nezer C, Daube G, Devlieghere F. Psychrotrophic lactic acid bacteria associated with production batch recalls and sporadic cases of early spoilage in Belgium between 2010 and 2014. Int J Food Microbiol. 2014;191:157-63.

12. Hultman J, Rahkila R, Ali J, Rousu J, Björkroth KJ. Meat processing plant microbiome and contamination patterns of cold-tolerant bacteria causing food safety and spoilage risks in the manufacture of vacuum-packaged cooked sausages. Appl Environ Microbiol. 2015;81:7088-97.

13. Rahkila R, Johansson P, Säde E, Paulin L, Auvinen P, Björkroth J. Multilocus sequence typing of Leuconostoc gelidum subsp. gasicomitatum, a psychrotrophic lactic acid bacterium causing spoilage of packaged perishable foods. Appl Environ Microbiol. 2015;81:2474-80.

14. Johansson P, Paulin L, Säde E, et al. Genome sequence of a food spoilage lactic acid bacterium, Leuconostoc gasicomitatum LMG $18811^{\top}$, in association with specific spoilage reactions. Appl Environ Microbiol. 2011;77:4344-51.
15. De Bruyne K, Schillinger U, Caroline L, et al. Leuconostoc holzapfelii sp. nov., isolated from Ethiopian coffee fermentation and assessment of sequence analysis of housekeeping genes from delineation of Leuconostoc species. Int J Syst Evol Microbiol. 2007;57:2952-9.

16. Björkroth J, Korkeala H. rRNA gene restriction patterns as a characterization tool for Lactobacillus sake strains producing ropy slime. Int J Food Microbiol. 1996:30:293-302.

17. Pitcher DG, Saunders NA, Owen RJ. Rapid extraction of bacterial genomic DNA with guanidium thiocyanate. Lett Appl Microbiol. 1989:8:151-6.

18. Staden R, Beal KF, Bonfield JK. The Staden package, 1998. Methods Mol Biol. 2000;132:115-30.

19. Delcher AL, Bratke KA, Powers EC, Salzberg SL. Identifying bacterial genes and endosymbiont DNA with Glimmer. Bioinformatics. 2007;23:673-9.

20. Hyatt D, Chen G-L, Locascio PF, Land ML, Larimer FW, Hauser LJ. Prodigal: prokaryotic gene recognition and translation initiation site identification. BMC Bioinformatics. 2010;11:119.

21. Aziz RK, Bartels D, Best AA, et al. The RAST Server: rapid annotations using subsystems technology. BMC Genomics. 2008;9:75.

22. Koskinen JP, Törönen P, Nokso-Koivisto J, Holm L. PANNZER - Highthroughput functional annotation of uncharacterized proteins in an errorprone environment. Bioinformatics. 2015:doi:10.1093/bioinformatics/btu851.

23. Pati A, Ivanova NN, Mikhailova N, et al. GenePRIMP: a gene prediction improvement pipeline for prokaryotic genomes. Nat Methods. 2010;7:455-7.

24. Antonov I, Borodovsky M. GeneTack: frameshift identification in protein-coding sequences by the Viterbi algorithm. J Bioinform Comput Biol. 2010;08:535-51.

25. Slater GSC, Birney E. Automated generation of heuristics for biological sequence comparison. BMC Bioinformatics. 2005:6:31.

26. de Jong A, van Heel AJ, Kok J, Kuipers OP. BAGEL2: mining for bacteriocins in genomic data. Nucleic Acids Res. 2010;38:W647-51. doi:10.1093/nar/gkq365.

27. Zhou Y, Liang Y, Lynch KH, Dennis JJ, Wishart DS. PHAST: a fast phage search tool. Nucleic Acids Res. 2011;39:W347-52. doi:10.1093/nar/gkr485.

28. Grissa I, Vergnaud G, Pourcel C. CRISPRFinder: a web tool to identify clustered regularly interspaced short palindromic repeats. Nucleic Acids Res. 2007:35:W52-7.

29. Lagesen $\mathrm{K}$, Hallin P, Rødland EA, Staerfeldt H-H, Rognes T, Ussery DW RNAmmer: consistent and rapid annotation of ribosomal RNA genes. Nucleic Acids Res. 2007;35:3100-8.

30. Lowe TM, Eddy SR. tRNAscan-SE: A program for improved detection of transfer RNA genes in genomic sequence. Nucleic Acids Res. 1997;25:0955-64.

31. Laslett D, Canback B. ARAGORN, a program to detect tRNA genes and tmRNA genes in nucleotide sequences. Nucleic Acids Res. 2004;32:11-6.

32. Krogh A, Larsson B, von Heijne G, Sonnhammer EL. Predicting transmembrane protein topology with a hidden Markov model: application to complete genomes. J Mol Biol. 2001;305:567-80.

33. Petersen TN, Brunak S, von Heijne G, Nielsen H. SignalP 4.0: discriminating signal peptides from transmembrane regions. Nat. Methods. 2011;8:785-6.

34. Klimke W, O'Donovan C, White O, et al. Solving the problem: genome annotation standards before the data deluge. Stand Genomic Sci. 2011;5:168-93.

35. Park I, Walsh CT. D-alanyl-D-lactate and D-alanyl-D-alanine synthesis by D-alanyl-D-alanine ligase from vancomycin-resistant Leuconostoc mesenteroides. J Biol Chem. 1997:272:9210-4.

36. Shipkowski S, Brenchley JE. Bioinformatic, genetic, and biochemical evidence that some glycoside hydrolase family 42 beta-galactosidases are arabinogalactan type I oligomer hydrolases. Appl Environ Microbiol. 2006;72:7730-8.

37. Zerbino DR, Birney E. Velvet: algorithms for de novo short read assembly using de Bruijn graphs. Genome Res. 2008;18:821-9.

38. Contreras-Moreira B, Vinuesa P. GET_HOMOLOGUES, a versatile software package for scalable and robust microbial pan-genome analysis. Appl Environ Microbiol. 2013:79.

39. Li L, Stoeckert CJ, Roos DS. OrthoMCL: identification of ortholog groups for eukaryotic genomes. Genome Res. 2003;13:2178-89.

40. Kaas RS, Friis C, Ussery DW, Aarestrup FM. Estimating variation within the genes and inferring the phylogeny of 186 sequenced diverse Escherichia coli genomes. BMC Genomics. 2012;13:577.

41. Roach DJ, Burton JN, Lee $C$, et al. A year of infection in the intensive care unit: prospective whole genome sequencing of bacterial clinical isolates reveals cryptic transmissions and novel microbiota. PLoS Genet. 2015;11, e1005413.

42. Rince A, Dufour A, Uguen P, Pennec JLE, De Ge L. Characterization of the lacticin 481 operon: the Lactococcus lactis genes ICtF, ICtE, and IctG encode a putative $A B C$ transporter involved in bacteriocin immunity. Appl Environ Microbiol. 1997;63:4252-60. 
43. Piard JC, Muriana PM, Desmazeaud MJ, Klaenhammer TR. Purification and partial characterization of lacticin 481, a lanthionine-containing bacteriocin produced by Lactococcus lactis subsp. lactis CNRZ 481. Appl Environ Microbiol. 1992:58:279-84.

44. Gokhale RS, Sankaranarayanan R, Mohanty D. Versatility of polyketide synthases in generating metabolic diversity. Curr Opin Struct Biol. 2007;17:736-43.

45. Patti JM, Jonsson H, Guss B, et al. Molecular characterization and expression of a gene encoding a Staphylococcus aureus collagen adhesin. J Biol Chem. 1992;267:4766-72.

46. Cramton SE, Gerke C, Schnell NF, Nichols WW, Götz F. The intercellular adhesion (ica) locus is present in Staphylococcus aureus and is required for biofilm formation. Infect Immun. 1999;67:5427-33.

47. Feltcher ME, Braunstein M. Emerging themes in SecA2-mediated protein export. Nat Rev Microbiol. 2012;10:779-89.

48. Field D, Garrity G, Gray T, et al. The minimum information about a genome sequence (MIGS) specification. Nat Biotechnol. 2008;26:541-7.

49. Woese CR, Kandler O, Wheelis ML. Towards a natural system of organisms: proposal for the domains Archaea, Bacteria, and Eucarya. Proc Natl Acad Sci U S A. 1990;87:4576-9.

50. Gibbons NE, Murray RGE. Proposals concerning the higher taxa of Bacteria. Int J Syst Bacteriol. 1978;28:1-6.

51. Garrity G, Holt J. The Road Map to the Manual. In: Boone D, Castenholz R, Garrity G, editors. Bergey's Manual of Systematic Bacteriology. 2nd ed. New York: Springer; 2001. p. 119-66.

52. Ludwig W, Schleifer K-H, Whitman WB. Class I. Bacilli class nov. In: De Vos P, Garrity G, Jones D, et al., editors. Bergey's Manual of Systematic Bacteriology. Secondth ed. New York: Springer; 2009. p. 19-20.

53. Ludwig W, Schleifer K-H, Whitman WB. Order II. Lactobacillales ord. nov. In: De Vos P, Garrity G, Jones D, De Vos P, Garrity G, Jones D, et al., editors. Bergey's Manual of Systematic Bacteriology. 2nd ed. New York: Springer; 2009. p. 464.

54. Schleifer K-H, Family V. Leuconostocaceae fam. nov. In: De Vos P, Garrity G, Jones D, et al., editors. Bergey's Manual of Systematic Bacteriology. 2nd ed. New York: Springer; 2009. p. 624.

55. van Tieghem P. Sur la gomme de sucrerie (Leuconostoc mesenteroides). Ann des Sci Nat Bot. 1878;7:180-203.

56. Garvie El. Genus Leuconostoc van Tieghem 1878, 198AL emend. mut. char. Hucker and Pederson 1930, 66AL. In: Sneath, Mair, Sharpe, Holt, editors. Bergey's Manual of Systematic Bacteriology. Baltimore: The Williams and Wilkins Co; 1986. p. 1071-5.

57. Skerman V, McGowan V, Sneath P. Approved lists of bacterial names. Int I Syst Bacteriol. 1980;30:225-420.

58. Nieminen T, Sade E, Endo A, Johansson P, Bjorkroth J. The Family Leuconostocaceae. In: Rosenberg E, DeLong E, Lory S, Stackebrandt E, Thompson F, editors. The Prokaryotes - Firmicutes and Tenericutes. Berlin Heidelberg: Springer; 2014. p. 215-40.

59. Björkroth J, Holzapfel W. Genera Leuconostoc, Oenococcus and Weissella. In: Dworkin M, editor. The prokaryotes: a handbook on the biology of bacteria: Firmicutes, Cyanobacteria, vol. 4. 3rd ed. New York: Springer; 2006. p. 267-319.

60. Ashburner M, Ball CA, Blake JA, et al. Gene Ontology : tool for the unification of biology. Nat Genet. 2000;25:25-9.

61. Boc A, Diallo AB, Makarenkov V. T-REX: a web server for inferring, validating and visualizing phylogenetic trees and networks. Nucleic Acids Res. 2012;40:W573-9.

62. Edgar RC. MUSCLE: multiple sequence alignment with high accuracy and high throughput. Nucleic Acid Res. 2004;32:1792-7.

63. Castresana J. Selection of conserved blocks from multiple alignments for their use in phylogenetic analysis. Mol Biol Evol. 2000;17:540-52.

64. Stamatakis A. RAxML-VI-HPC: maximum likelihood-based phylogenetic analyses with thousands of taxa and mixed models. Bioinformatics. 2006:22:2688-90.

65. Kim D-S, Choi S-H, Kim D-W, et al. Genome sequence of Leuconostoc inhae KCTC 3774, isolated from kimchi. J Bacteriol. 2011;193:1278-9.

66. Felsenstein J. PHYLIP - Phylogeny Inference Package (Version 3.2). Cladistics. 1989:5:164-6.

67. Alikhan N-F, Petty NK, Ben Zakour NL, Beatson SA. BLAST Ring Image Generator (BRIG): simple prokaryote genome comparisons. BMC Genomics. 2011;12:402.

\section{Submit your next manuscript to BioMed Central and we will help you at every step:}

- We accept pre-submission inquiries

- Our selector tool helps you to find the most relevant journal

- We provide round the clock customer support

- Convenient online submission

- Thorough peer review

- Inclusion in PubMed and all major indexing services

- Maximum visibility for your research

Submit your manuscript at www.biomedcentral.com/submit

) Biomed Central 